\title{
指屈筋腱綎合術における補助綎合方法の検討
}

\author{
下戸 健 ${ }^{* 1}$, 白石 善孝 ${ }^{* 2}$, 石川 篤*3, 日垣 秀彦 ${ }^{* 4}$ \\ 松田 匡弘 ${ }^{* 5}$, 光安 廣倫 ${ }^{* 6}$, 岩本 幸英 ${ }^{* 7}$, 三浦 裕正 ${ }^{* 8}$
}

\section{Investigation of peripheral sutures method in Flexor Tendon Repair}

\author{
Takeshi SHIMOTO ${ }^{* 1}$, Yoshitaka SHIRAISHI, Atsushi ISHIKAWA, Hidehiko HIGAKI, \\ Masahiro MATSUDA, Hiromichi MITSUYASU, Yukihide IWAMOTO and Hiromasa MIURA \\ ${ }^{* 1}$ Fukuoka Institute of Technology, Dept. of Information and Systems Engineering \\ Wajiro-higashi 3-30-1, Higashi-ku, Fukuoka, 811-0295 Japan
}

In performing the flexor tendon repair, peripheral suture is essential to improve the sufficient strength and to accomplish the early active mobilization of repaired flexor tendons. It has been reported the interlocking cross-stitch peripheral suture is increased the strength. The purpose of this study was to evaluate about various interlocking cross-stitch peripheral suture under cyclic loading conditions. Artificial rolls, Parotisrolls ${ }^{\mathrm{TM}}$ were used as the experimental model in this study. We sutured the end of the two artificial rolls using a combination of peripheral sutures. All pairs of the artificial roll tendon model were sutured using only peripheral sutures with 6-0 Polypropylene. The suture bites were placed $2 \mathrm{~mm}, 3 \mathrm{~mm}, 4 \mathrm{~mm}, 5 \mathrm{~mm}, 6 \mathrm{~mm}, 8 \mathrm{~mm}$ and $12 \mathrm{~mm}$ away from the end of the roll. Each bite was approximately $1 \mathrm{~mm}$ in depth and the size of transverse segments of each cross-stitch suture was $4 \mathrm{~mm}$. An initial cyclic load of $10 \mathrm{~N}$ for 500 cycles was applied and increased by $5 \mathrm{~N}$ for an additional 500 cycles at each new load until rupture. In result, the interlocking cross-stitch peripheral suture that the suture bite distance is long, improved the strength of the specimen. However, in the face of realization of smooth motion after flexor tendon repair, suture bite of $8 \mathrm{~mm}$ or more is unrealistic. Therefore, it was considered to be valid suture bite of $8 \mathrm{~mm}$ from $5 \mathrm{~mm}$.

Key Words : Tendon and ligament, Flexor tendon repair, Cyclic loading, Interlocking cross-stitch suture

\section{1. 緒言}

臨床において，指屈筋腱の断裂や損傷に対し治療が必要な場合，最良の治療法として腱縫合術が利用される. 手掌遠位から中節部を指す zoneII での屈筋腱断裂や損傷後の指の機能回復は困難とされており, その理由として, 深指屈筋腱と浅指屈筋腱の二つが腱鞘に密集していることが挙げられる.さらに，1つの腱だけが切れる怪我は なく, 皮膚・血管・神経・腱鞘と周りの組織も損傷している場合が多く, 縫合した腱は周りの組織も一緒に創傷 治癒されるため癒着が起こる，腱の癒着をできるだけ防ぐには，早期に損傷した指を運動させ，腱と周りの組織 の滑走を促すことが重要である，指屈筋腱を縫合により再建する場合は，腱中央部を縫合する主縫合を行い，場 合によっては腱周囲の補助縫合を行う。主縫合は必ず行われる縫合であり強度に大きく影響する. 補助縫合は腱 断端部の表面を平滑，すなわち瘉着防止のために行われるが，近年の研究では，補助縫合も強度に影響している と考えられている(1). したがって, 破断せずに必要な力に耐えうる十分強い補助縫合方法が模索されている.

屈筋腱の強度試験は Pruitt の研究(2)以来, 引張試験よりも繰返し引張試験の方が生理的で鋭敏な試験であると考 えられるようになったが，周期的負荷試験を用いて両者を比較検討した報告はこれまでなかった. そこで本研究

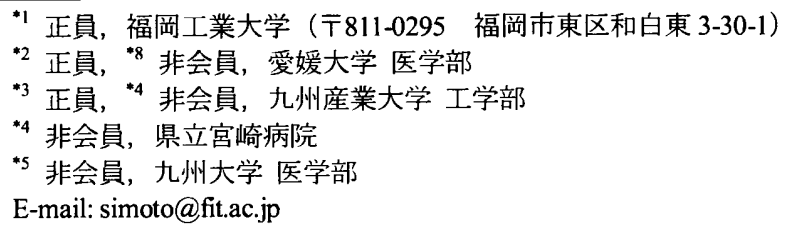

[No.12-1］日本機械学会 2012 年度年次大会講演論文集 [2012.9.9-12, 金沢] 
グループでは, Running suture, Standard cross-stitch suture, Interlocking cross-stitch suture の 3 種類の補助縫合方法 で作製した腱縫合モデルに対し，生体内環境を考慮した繰り返し引張試験を行い， Interlocking cross-stitch suture が縫合力を強める有効な方法の 1 つとなりうることを報告している(3). しかし，臨床応用を考慮した場合，術者 ごとで針を通す位置が異なる等で, 強度の再現性が得られないことが挙げられる. そこで本研究では, Interlocking cross-stitch sutureにおいて, 針を通す位置を変化させて繰り返し荷重試験および単純引張試験を行い, 縫合方法に ついて検討した.

\section{2. 対象および方法}

指屈筋腱は, 体格, 体重, 性別や年齢などの個体の違いによって径が様々であり, 径について記載のある文献 は非常に少ない(4).そのため，一定の径を用いた試験を行うことは困難である。そこで本研究では，均一な径を 維持して力学試験を行うために，人工材料である Parotisrolls ${ }^{\mathrm{TM}}$ (Coltene/Whaledent Gmbhp+Co., Germany)を選択し た. 人間の指屈筋腱と比較し張力の絶対值は異なるが，バイオメカニカル評価を行うのに有効な指屈筋腱モデル とされている ${ }^{(3)}$. Parotisroll の径は統計学的に有意差がないことを確認し，試験片の直径と長さはそれぞれ $8 \mathrm{~mm}$

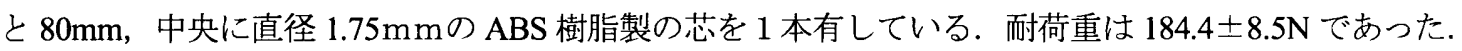

Parotisroll を 2 本用いて断裂した腱を再現し，主縫合は行わず， Interlocking cross-stitch suture で補助縫合を行つ た．縫合禾は 6-0 Polypropylene を使用し，両 Cross-stitch の Transverse segment 4mm，深さを $1 \mathrm{~mm}$ ，ストラン ド数を 12 とした. Suture bite $2 \mathrm{~mm}, 3 \mathrm{~mm}, 4 \mathrm{~mm}, 5 \mathrm{~mm}, 6 \mathrm{~mm}, 8 \mathrm{~mm}, 12 \mathrm{~mm}$ および $16 \mathrm{~mm}$ と変化させ，全周 縫合したものを用意した。それに合わせて，名称を CS4-2，CS4-3，CS4-4，CS4-5，CS4-6，CS4-8，CS4-12 およ びCS4-16 とした（表 1)。縫合は全て一人の医師が行い，一貫性を保つようにした。

繰り返し荷重試験には作製した試験機を用いた（図 1). 縫合された試験片をサイクリック試験機の上下のクラ ンプに固定し，クランプ閒の距離を $20 \mathrm{~mm}$ で設置した．ステッピングモータを PC で制御し，パネルに固定され た下方のクランプが上下方向に動作することで, 負荷が縫合部位を通って掛かる構造となっている. 引つ張り荷

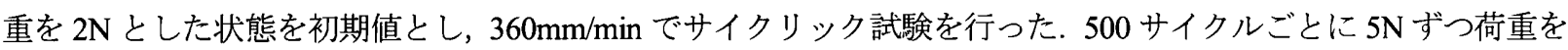
増加させ，試験片の縫合糸が破断するか，試験片の素材が破断するまで試験を行った.

Table 1 Materials data of the experiment

\begin{tabular}{lccccc} 
Name & Suture bite & $\begin{array}{c}\text { Transverse } \\
\text { segment } \\
(\mathrm{mm})\end{array}$ & $\begin{array}{c}\text { Depth } \\
(\mathrm{mm})\end{array}$ & $\begin{array}{c}\text { Core } \\
\text { suture } \\
\text { (strands) }\end{array}$ & $\begin{array}{c}\text { Peripheral } \\
\text { suture } \\
(\text { strands) }\end{array}$ \\
\hline CS4-2 & 2 & 4 & 1 & 0 & 12 \\
CS4-3 & 3 & 4 & 1 & 0 & 12 \\
CS4-4 & 4 & 4 & 1 & 0 & 12 \\
CS4-5 & 5 & 4 & 1 & 0 & 12 \\
CS4-6 & 6 & 4 & 1 & 0 & 12 \\
CS4-8 & 8 & 4 & 1 & 0 & 12 \\
CS4-12 & 12 & 4 & 1 & 0 & 12 \\
CS4-16 & 16 & 4 & 1 & 0 & 12
\end{tabular}

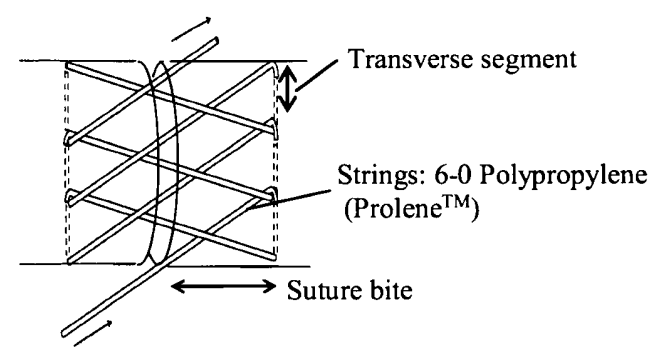

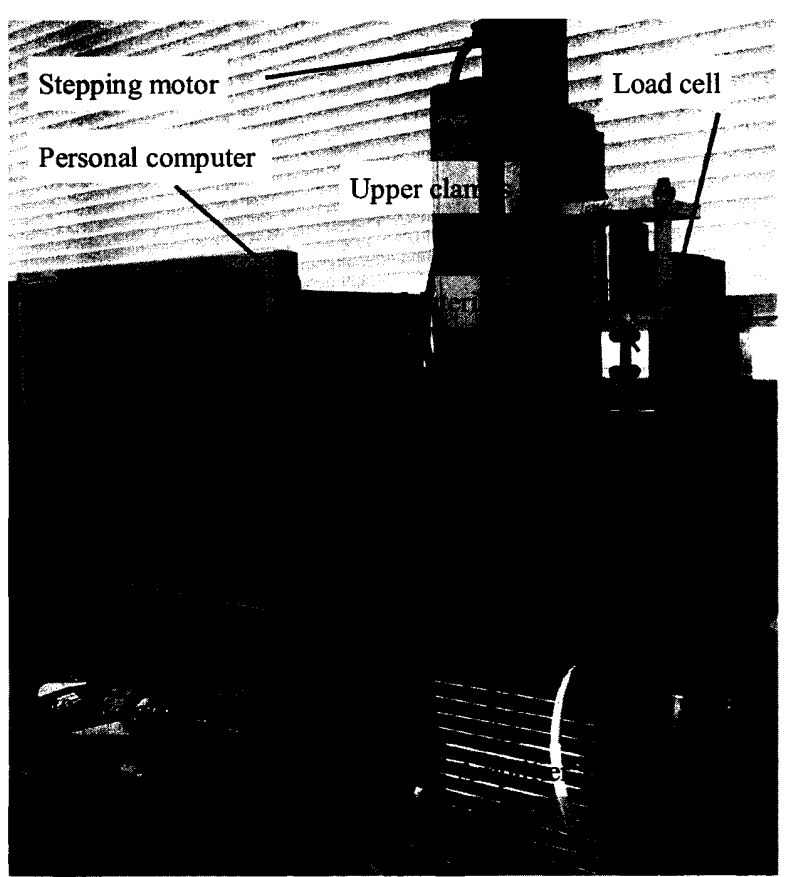

Fig.1 Schema of cyclic loading machine 
単純引張試験には万能試験機 Instron 5867 を用いた。縫合された試験片を万能試験機の上下のクランプに固定 し, クランプ間の距離を $20 \mathrm{~mm}$ で設置した. 引張り荷重の初期值を $0 \mathrm{~N}$ とし， $1 \mathrm{~mm} / \mathrm{min}$ で単純引張試験を行い， 縫合系もしくは試験片の素材が破断するまで試験を行った.

\section{3. 結果および考察}

単純引張試験および繰り返し荷重試験における最大破断張力の結果を図 2 に示す．単純引張試験の結果におい

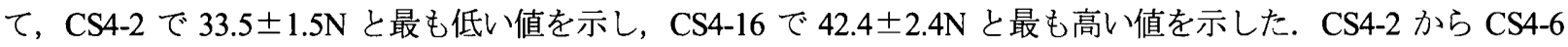
まで最大破断張力は増加傾向であったが, CS4-8 で有意に減少し, CS4-12, CS4-16 では再び増加傾向であった. 繰り返し荷重試験の結果において, CS4-2, CS4-3 およびCS4-4 では 25.0N, CS4-5, CS4-6 および CS4-8 では 30.0N, CS4-12 およびCS4-16 では 32.0 2.7N で破断した. 繰り返し荷重試験の最大破断張力の結果では, 単純引張り試 験よりも低い值を示した．繰り返し荷重試験では，縫合糸および試験片に繰り返し負荷が掛かったため，縫合系 は伸縮を繰り返し，試験片は伸縮に加え縫合系に引っ張られることにより断面積が大きく変動してした。 したが って, 疲労により繰り返し荷重試験の最大破断張力は単純引張り試験の結果よりも低い值を示したと考えられる.

縫合系もしくは試験片が破断するまでのサイクル数の結果を図 3 に示寸.CS4-2 で $1575.6 \pm 57.5$ サイクルと最 も低い值を示し，CS4-16 で2348 178.2 サイクルと最も高い值を示した. Suture bite を長くするにつれサイクル 数は上昇する傾向が確認された. CS4-2, CS4-3 およびCS4-4 では, 他と比較しサイクル数が少なく, 縫合系での 破断も確認された. CS4-4 と CS4-5 では，有意にサイクル数が上昇しており，CS4-5，CS4-6およびCS4-8 はデー 夕のばらつきが小さかった. CS4-8 扩よびCS4-12 間で再び有意にサイクル数は増加するが，ばらつきは大きかっ た.

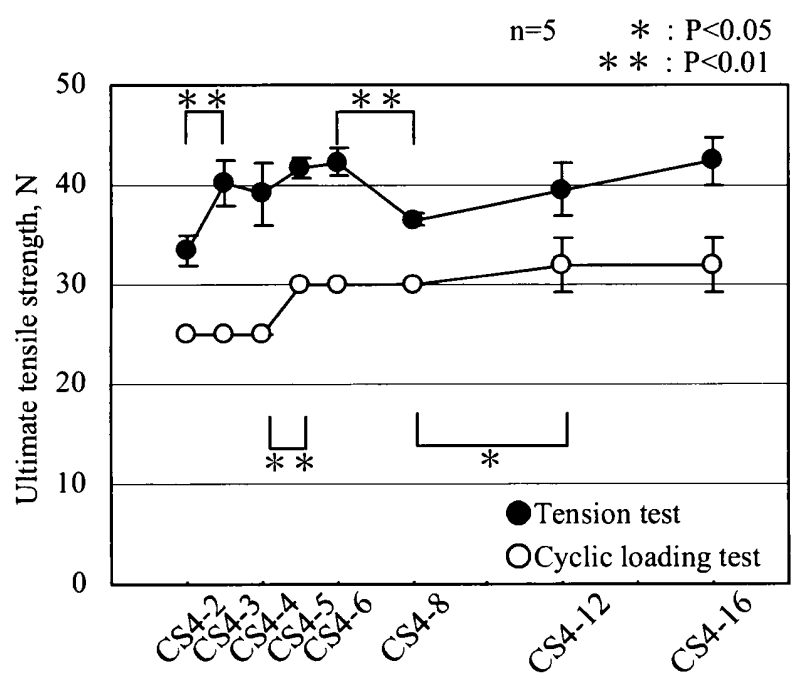

Fig2. Comparison of the ultimate tensile strength

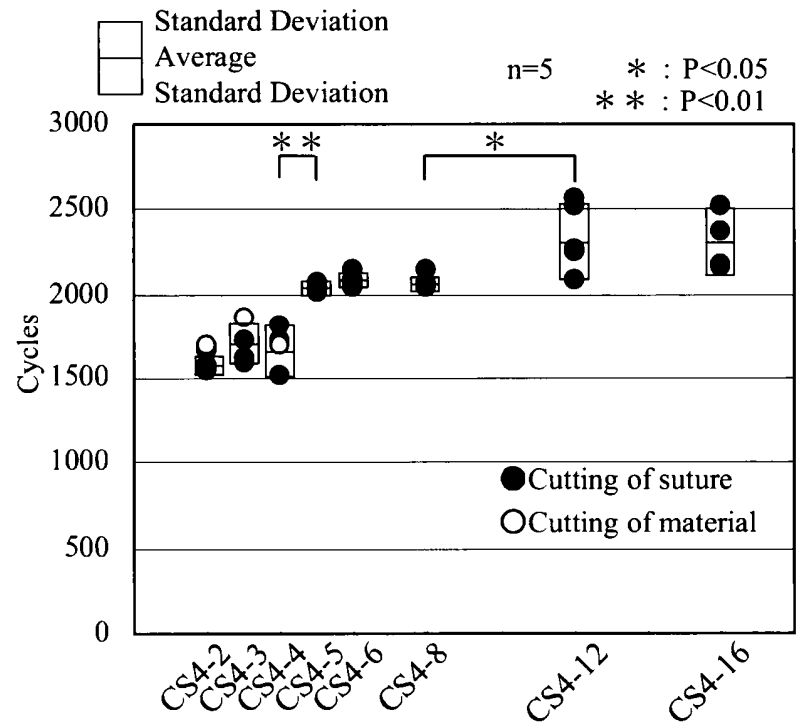

Fig3. Comparison of the fatigue strength

単純引張試験および繰り返し荷重試験の結果から，CS4-2 から CS4-4，CS4-5 から CS4-8，CS4-12 から CS4-16 の 3 群に分けられる.CS4-2 から CS4-4 の群では，他の試料よりもサイクル数が少なく，試験片での破断が確認 できたことからも，指屈筋腱縫合術を施した場合に指屈筋腱へ負荷が掛かっていると予想され，指屈筋腱を破損 させる可能性があると考えられる. CS4-5 から CS4-8 の群では，全ての試料は縫合系で破断していたことから， 指屈筋腱に及ぼ寸負荷は小さいと推測される. CS4-12 から CS4-16 の群では, CS4-5 から CS4-8 の群と同様のこ とが言えるが，最大破断張力と破断時までのサイクル数のデータのばらつきが大きく， Suture bite が $12 \mathrm{~mm}$ 以上 では一定の効果が得られないことが考えられる．さらに，補助縫合の役割は腱縫合部の平滑な動きを実現するこ とである. Suture biteが $12 \mathrm{~mm}$ 以上では，試験片端面間のずれが大きくなりやすくなる.したがって，平滑な動 
きを実現することができなくなり，手術後のリスクが高くなると考えられる.これらのことから, Suture bite は $5 \mathrm{~mm}$ から $8 \mathrm{~mm}$ にすることが有効であることが考えられる.

\section{4. 結 語}

実験装置を用いて，指屈筋腱縫合術における Interlocking cross-stitch suture の Suture biteに変化を与え, 繰り返 し荷重試験および単純引張試験にて評価した. CS4-2, CS4-3 およびCS4-4については, 指屈筇腱縫合術を施した 場合に指屈筋腱への負荷が掛かっていると予想され，指屈筋腱を破損させる可能性があると考えられた.さらに， 持続性も低いため縫合には適していないことが考えられた．CS4-5 以上については，荷重が縫合系と試験片に分 散され，他の縫合方法と比較し大きな強度を確保できることが考えられた. Suture bite は $5 \mathrm{~mm}, 6 \mathrm{~mm}, 8 \mathrm{~mm}, 12 \mathrm{~mm}$, $16 \mathrm{~mm}$ と長くなるに伴い，試料の強度が増していることが確認できたが，指屈筋腱縫合後の平滑な動きの実現を 考慮した場合, Suture bite は $5 \mathrm{~mm}$ から $8 \mathrm{~mm}$ にすることが患者への負担が掛からず，強度が高い縫合方法という ことが確認された。本研究は指屈筋腱縫合術における Interlocking cross-stitch suture $の$ Suture bite に変化を与えた が, strand 数や depth, Transverse segment に変化を与える場合など, 様々な縫合方法を模索する上で本研究のよう な実験は有効であると考えられる。

\section{文献}

(1) Ansari, U., Lawson, R.D., Peterson, J.L., Appleyard, R.C. and Tonkin, M,A., "Effect of partial versus complete circumferential repair on flexor tendon strength in cadavers", the Journal of Hand Surgery, Vol.34, No.10, (2009), pp.1771-6.

(2) Pruitt, D. L., Manske, P.R. and Fink, B., "Cyclic stress analysis of flexor tendon repair", the Journal of Hand Surgery, Vol.16, No.4, (1991), pp.701-7.

(3) Takeuchi, N., Mitsuyasu, H., Hotokezaka, S., Miura, H., Higaki, H. and Iwamoto, Y., "Strength enhancement of the interlocking mechanism in cross-stitch peripheral sutures for flexor tendon repair: biomechanical comparisons by cyclic loading", the Journal of Hand Surgery (European Volume), Vol.35, No.1, (2009), pp.46-50.

(4) Mishra, V., Kuiper, J.H. and Kelly, C.P., "Influence of core suture material and peripheral repair technique on the strength of Kessler flexor tendon repair", the Journal of Hand Surgery (Edinburgh Scotland), Vol.28, No.4, (2003), pp.357-62. 